\title{
A cartografia escolar e o desenvolvimento da habilidade espacial
}

Resumo: A representação visual do espaço geográfico é, por excelência, o mapa. Como linguagem, sua utilização requer mais do que o aprendizado dos signos e do como dispor os objetos em uma carta, mas de um aprendizado desenvolvido no âmbito da habilidade espacial. O presente texto tem como propósito refletir sobre o desenvolvimento desta habilidade para o aprendizado da Geografia, no sentido de ampliar os conhecimentos cartográficos dos professores, bem como suas capacidades para visualizar as extensões, fluxos e intensidades dos distintos fenômenos e fatos geográficos, e assim contribuir para um melhor encaminhamento dos estudos de Geografia no ensino médio.

\section{School cartography and the development of spatial ability}

Abstract: The map is, for excellence, a visual representation of geography space. As a language, the use of maps requires more than learning the signs and how to arrange the objects on them, but depends on a skill in the context of spatial intelligence. The present paper has as purpose to reflect upon the spatial ability in geography teaching and aims to extend knowledge of teachers in their use of cartography, as well as their ability for visualization of extensions, fluxes and intensities of the different geographical phenomena and facts, and so contribute to improve studies of high school geography.
Ricardo Vicente Ferreira *

*Professor do Departamento de Geografia da Universidade Federal do Triângulo Mineiro

\section{Palavras-chave:}

Representações espaciais; Cartografia escolar; Ensino médio; Visualização espacial.

Key-Words: Spatial representations; School cartography; High school; Spatial visualization. 


\section{Introdução}

A representação mental do espaço geográfico pode ser vista a partir da operação de duas idealizações: uma que se constrói com base no que se vê e vivência no espaço próximo, processada na mente por uma visualização da paisagem concreta na escala local; e outra imaginada abstratamente através da leitura esquemática de modelos e representações que faz a partir de mapas, imagens e/ou esquemas reportados às superfícies territoriais mais extensas, como estados, países, continentes ou o mundo.

É importante pensar novas proposições de abordagem sobre o uso de representações no campo do ensino de Geografia, sobretudo, para os níveis seriais mais adiantados do ensino básico, pois, para estes estudantes, as experiências com o espaço são mais amplas em relação à idade infantil. Entende-se que é necessário compreender um princípio inerente à cognição humana: a habilidade espacial e, assim, estabelecer uma pauta para debates.

Nesta exposição, faz-se uma reflexão sobre questões da visualização geométrica e dimensionada do espaço geográfico em mapas e cartogramas e, a partir daí, discute-se sua importância no ensino de Geografia.

O termo habilidade é recorrente nos textos pedagógicos e nos materiais de orientação em ensino. No entanto, percebe-se que, na prática, a verificação do aprendizado das variadas aptidões requeridas ao longo do processo educativo são feitas por meio de aplicações formais, estabelecidas nos atos relacionados à leitura, produção e interpretação de texto - práticas linguísticas - e na resolução de exercícios, problemas e fórmulas, que são procedimentos relacionados ao raciocínio lógico-matemático.

As habilidades estão associadas às competências do ser humano para realizar tarefas, ou ainda, às aptidões humanas para resolver problemas e tomar decisões diante de situações diversas. Descoladas de uma referência que especifique sua natureza, tanto o termo "habilidade", quanto o termo "competência", são palavras de significado vago. Na educação estes termos são recorrentes e, em muitos casos, aparecem de maneira isolada, sem a clara associação ou especificação do pensamento ou assunto sobre o qual versam. No caso da Geografia, como em outras ciências, o processo de aprendizagem implica no desenvolvimento de uma infinidade de aptidões, tais como: fazer relações entre fatos e fenômenos; interpretar imagens, textos, símbolos e representações; formular ideias a partir de saberes sobre como a sociedade e da natureza se organizam no plano espacial. Aqui se faz uma observação sobre o desenvolvimento das aptidões para analisar representações do espaço geográfico feitas em mapas e diagramas. Este é um conhecimento que requer habilidade espacial, questão pouco explorada pela Geografia em sua prática escolar.

Quando se fala em representação do espaço, logo se pensa no mapa. Sem dúvida, o mapa expressa o meio pelo qual se "lê" o espaço a partir de uma visão aérea. Ainda que diferentes temas possam estar associados à cartografia geográfica, a idéia de se estar observando parte da superfície ou toda a Terra a partir do alto é uma verdade para qualquer representação em mapas. A leitura do mapa subentende a compreensão do espaço representado, e esta é uma ação que requer a abstração. A percepção espacial do lugar se inicia nos primeiros anos de vida e evolui gradativamente ao longo do tempo. Esta faculdade é resultado do acúmulo de experiências obtidas através das atividades humanas, tais como: a movimentação consciente por diversas paisagens; a percepção de direção e orientação a partir de referenciais astronômicos, como o sol e outros astros; 0 exercício da localização e posicionamento no espaço, geralmente feito com base em marcos naturais e artificiais na superfície terrestre; entre outras.

A iniciação aos mapas deve provocar o exercício funções espaciais importantes no indivíduo, p. $71-80$, jan./abr. 2013

A cartografia escolar e o desenvolvimento da habilidade espacial como a lateralidade e a orientação, que são aptidões inatas e elementos fundamentais para a alfabetização cartográfica, da mesma forma como a fala é um pressuposto significativo para a iniciação à escrita formal.

Debater a prática do professor de Geografia diante destas questões parece relevante, uma vez que a representação que traduz a realidade na forma de um modelo esquemático - o mapa - e sua 
leitura depende do desenvolvimento de uma habilidade, a espacial. Nesse sentido, aqui se discute sobre o uso do recurso da visualização de mapas e cartogramas na prática do ensino de Geografia. Entende-se que se deve investir no aprendizado da habilidade espacial junto aos alunos como condição sine qua non para leitura de mapas, pois sem ela as interpretações correm o risco de se tornarem subjetivas.

Existe uma disponibilidade de literaturas e pesquisas que se reportam a alfabetização cartográfica, porém aqui destacamos quatro publicações frequentemente citadas em artigos e estudos sobre o assunto: Simielli (1999); Almeida e Passini (1988); Almeida (2001); Souza e Katuta (2001). Nesses trabalhos são abordadas questões do aprendizado das crianças nos níveis seriais iniciais, dentre outras questões, tratam do processo de aquisição da linguagem cartográfica, que implica no domínio e aprendizado símbolos, bem como, na compreensão de seus significados nos mapas. A educação cartográfica para os níveis seriais mais adiantados (ensino médio) e para a educação de jovens e adultos requer uma atenção diferenciada e carece de maiores aprofundamentos metodológicos sobre o uso dos mapas. No texto de Simielli (1999) há uma proposição metodológica clara de como encaminhar o aprendizado da cartografia em diferentes níveis seriais, e atende a diferentes etapas da cognição da linguagem cartográfica. No caso do ensino médio, os encaminhamentos devem se dar em direção à análise espacial, com possibilidades de se fazer correlações e síntese de mapas. No entanto, a autora chama a atenção para o fato de que, nas escolas, os professores tendem a trabalhar com propostas muito elementares, que evoluem apenas ao nível da localização e análise do fenômeno mapeado, que é o nível mais elementar de se trabalhar com mapas em sala de aula (ibidem, p. 102). Uma publicação bastante citada em artigos e pesquisas sobre o uso da cartografia no ensino médio é de Santos (2003), em seu artigo são feitas considerações de ordem conceitual da cartografia temática e de como este conhecimento deve ser compreendido pelos professores no ensino médio. 0 autor revê princípios da cartografia temática, sobretudo os apresentados por Bertin e Martinelli, e reitera a necessidade de se verificar questões teóricas e científicas que pressupõe o ensino da cartografia na escola.

As publicações supracitadas tocam em questões fundamentais do ensino da cartografia no contexto da disciplina Geografia. Contudo, aqui há uma preocupação adicional que remete à seguinte indagação: como professores e alunos concebem na mente o espaço lido no mapa?

Os estudantes do ensino médio e da educação de jovens e adultos (EJA) tendem a possuir experiências mais amplas com o espaço, e isso significa que, parte da aptidão que estes indivíduos possuem para formar e recuperar mentalmente as imagens do espaço geográfico, resulta da vivência que tem com o lugar e com a cidade onde habitam. Há que se considerar, ainda, as experiências mais amplas de alguns, por exemplo, aquelas adquiridas quando realizaram viagens, ou mesmo, quando puderam morar em diferentes lugares (cidades, estados, países).

A adoção de uma metodologia específica para o aprendizado da cartografia e da visualização espacial pressupõe que alguns conhecimentos são comuns à maioria dos estudantes e se consolidam com o tempo. As proposições para o docente em seu trabalho com a alfabetização cartográfica, geralmente, se fazem a partir de uma realidade infantil, que aborda práticas da experiência da criança com o espaço. Assim, pensa-se que as experiências com o espaço adquiridas por um indivíduo que está passando da infância para a juventude, no caso do ensino médio, e do jovem e adulto, no caso da EJA, devem ser vistas de maneira diferenciada.

Com base nestas questões, propõe-se uma pauta para debates que se aporta na condição de um convite à reflexão.

\section{Compreensão da Habilidade Espacial}

O uso do termo habilidade é recorrente no campo do ensino e se aplica a diferentes abordagens em educação. Uma consulta aos Parâmetros Curriculares Nacional permite, rapidamente, verificar que esta qualidade acompanha as orientações para a aprendizagem das distintas áreas do conhecimento e temas transversais da educação básica1.
$1 \mathrm{Na}$ introdução aos PCN, 0 termo "habilidade" aparece 23 vezes. As primeiras referências à palavra estão associadas aos distintos componentes curriculares e temas transversais que integram a educação básica.

Geografia Ensino \& Pesquisa, v. 17, n.1 p. $71-80$, jan./abr. 2013

Ferreira, R. V.

ISSN 2236-4994 
Em linhas gerais, as habilidades são adquiridas pela prática, e implicam no desenvolvimento de capacidades que, comumente, estão associadas aos atos para a realização de tarefas de maneira rápida ou de forma mais ágil do que se faria sem o exercício dos procedimentos que conduzem o raciocínio das ações.

O desenvolvimento de habilidades específicas é necessário a qualquer aprendizado, no entanto, a prática escolar tem revelado que, exceto para alguns componentes curriculares como as Artes e a Educação Física, sua aquisição no processo de ensino-aprendizagem tem se reservado à aplicação de testes e tarefas formais. Todavia, é provável que essa prática seja resultado mais de uma ação viciada em sala de aula, do que propriamente de objetivos concretos dos programas de ensino ou mesmo das aspirações docentes. É igualmente provável que isso tenha a ver com a realidade que acompanha a vida escolar, que regularmente avalia os conhecimentos dos alunos pela aplicação de provas e testes escritos estruturados em um modelo que exige, essencialmente, a demonstração das habilidades linguísticas e lógico-matemáticas.

Na década de 1980, Howard Gardner iniciou um programa de pesquisa relacionado às capacidades humanas de cognição e aprendizado. Com foco orientado na inteligência humana para a realização de diversas tarefas, resolução de problemas e elaboração de produtos, o resultado da ampla investigação conduzida pelo grupo de pesquisa orientado por Gardner foi de que é possível identificar sete principais inteligências, dentre uma imensa massa de informações relativas às capacidades cognitivas e de habilidades do ser humano, a saber: inteligência musical, inteligência corporal-cinestésica, inteligência lógico-matemática, inteligência lingüística, inteligência espacial, inteligência interpessoal, inteligência intrapessoal (Gardner, 1995). A inteligência espacial se relaciona, entre outras coisas, à aptidão humana para a resolução de problemas relacionados à navegação e ao uso do sistema notacional de mapas (ibidem, p. 26).

Tendo por base as asserções de Gardner, no que diz respeito à inteligência espacial voltada às questões do aprendizado escolar, entende-se que a Geografia é a disciplina que oferece maiores aberturas para 0 aprendizado das habilidades espaciais, juntamente com a geometria. Nesse sentido, uma vez que os mapas são os recursos utilizados para se fazer análises, o aprendizado das representações cartográficas deve ser refletido com maior profundidade, tendo como um dos propósitos o desenvolvimento da visualização das cartas, dos diagramas, das projeções do planisfério e dos globos. É importante o exercício das visualizações tridimensionais e 0 armazenamento das modificações produzidas, quando, por exemplo, os modelos são rotacionados ou deslocadas suas orientações. Todo esse conteúdo depende da habilidade humana para formar, reter, recuperar e transformar imagens visuais (CARROLL, 1993, p.305) em esquemas e representações.

Em relação à cartografia escolar, duas observações devem ser feitas sobre o modo como se conduz o raciocínio no aprendizado das representações. Na sala de aula, não se pode correr o risco de encaminhamentos que confundam a ideia da geometria da Terra projetada no plano-bidimensional, com a de uma Terra verdadeiramente plana.

Quando se reporta à paisagem do entorno a construção mental do espaço não se faz da mesma forma daquela que se refere aos espaços mais extensos, como o território de um estado ou país. É natural esta distinção, pois as superfícies maiores não são tangíveis à visão e à própria vivência humana. Há uma propensão à desconsideração da realidade geométrica que perfaz a superfície curva da Terra. Isso ocorre porque a experiência humana se dá com base em uma "realidade plana" e não esférica. Ainda que a maioria dos estudantes e professores admita a esfericidade do globo terrestre, na prática, esta é uma experiência pouco concreta, senão, dada apenas no plano da ideia.

De um modo geral, é simples mentalizar o espaço geográfico da paisagem do entorno - a escola, o bairro e a cidade, pois esses são espaços tangíveis. No entanto, a imaginação de superfícies extensas, como o território de um estado, uma nação, um continente ou todo o planisfério, exige o exercício da abstração, pois se tratam de dimensões que ultrapassam os limites do pensamento construído no plano das vivências espaciais. 
A experiência em sala de aula tem revelado uma dificuldade por parte dos estudantes em construir, mentalmente, uma visualização do que é referido no plano cartográfico. A esse respeito convém destacar uma das representações mais recorrentes na aula de Geografia, a do planisfério. A visualização deste produto requer a habilidade da transposição mental de uma representação bidimensional para uma visualização tridimensional. Tomando como exemplo a figura 1, a direção que liga as cidades de Campinas (SP) e Tóquio (Japão) está representada pelo arco de linha que liga os pontos A-B, e o círculo que perfaria a volta pela Terra numa direção constante, se desenvolve no plano como um grande arco semelhante a letra ômega do alfabeto grego $(\Omega)$, as distorções da linha na porção sul do planisfério se deve a deformações da "quadrícula" promovida pela projeção Mollweide nas latitudes extremas.

No caso do planisfério, a visualização depende da interpretação da projeção, o que requer aptidões mais afinadas com o campo da geometria projetiva e exige do observador a capacidade de transpor mentalmente o objeto "esférico", a Terra, para o plano bidimensional, o mapa. Além disso, faz-se necessário a interpretação gráfica dos contornos dos continentes, territórios e oceanos projetados nesse plano. Em resumo, a visualização do planisfério demanda uma habilidade específica, aqui entendida como uma aptidão humana do campo da inteligência espacial.

Figura 1- Planisfério Mollweide com meridiano central em $150^{\circ}$ leste e circulo de referência contornando toda a Terra e atravessando as cidades de Campinas (SP) e Tóquio.

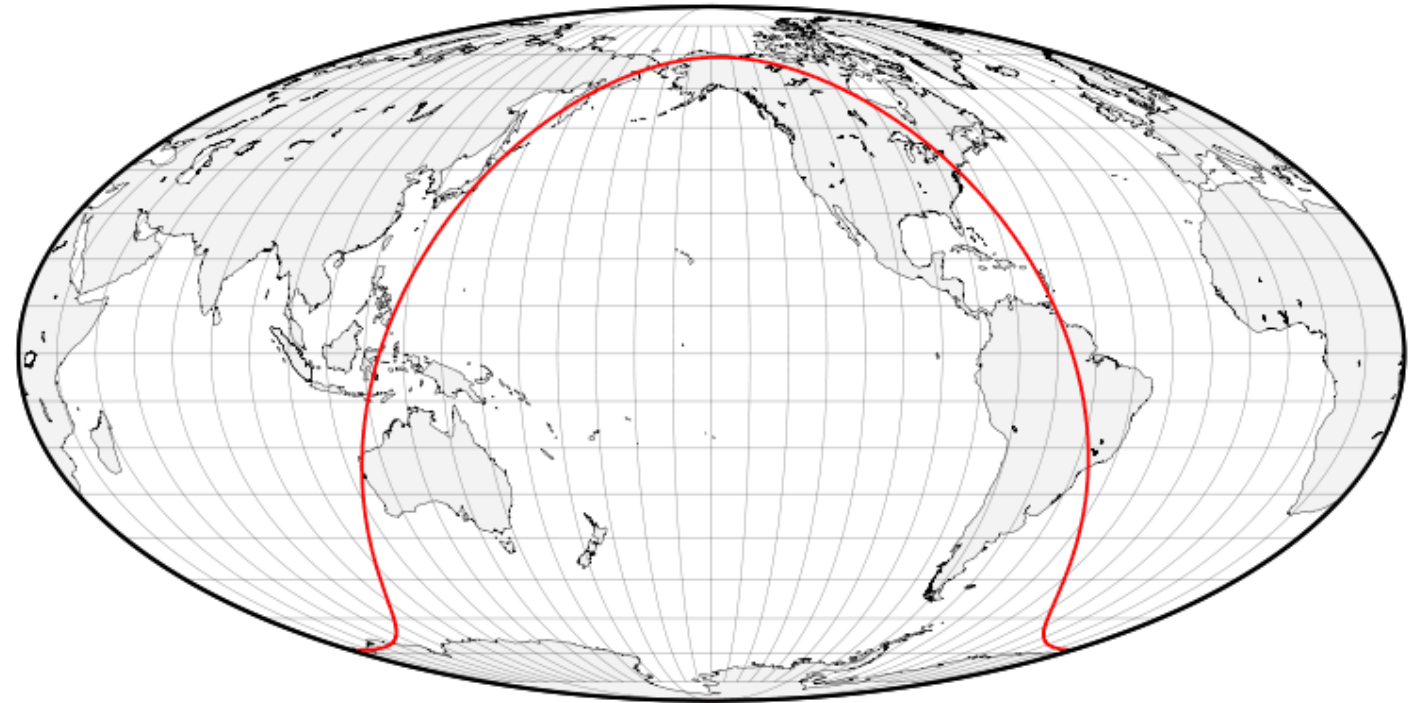

Fonte: < http://www.progonos.com/furuti/MapProj/CartIndex/cartlndex.html >

Segundo Park, Lubinski e Benbow (2010), esta cognição se define por uma capacidade de, mentalmente, fazer a produção, rotação e transformação de uma imagem que, no exemplo utilizado, trata-se de uma ação referida à representação do planisfério de Mollweide, uma projeção pseudocilíndrica com paralelos retilíneos cujos espaçamentos decrescem do equador em direção aos pólos e os meridianos se definem por elipses de diferentes amplitudes (exceto o meridiano central) que cortam os paralelos em partes iguais.

No que tange a visualização do espaço do entorno ou vivido, aquele que se refere ao lugar onde professores e alunos habitam, o raciocínio espacial é conduzido de uma maneira diferenciada. Nesse caso, a habilidade espacial se desenvolve em torno das capacidades para se orientar no espaço e para observar as dimensões/extensões das paisagens, à semelhança das aptidões para a orientação dos os antigos navegantes e exploradores dos continentes, só que em uma dimensão espacial menor. Por exemplo, nas cidades essas relações se dão por marcos na paisagem, construções, ruas, avenidas, topografia, entre outros. Em sala de aula, os professores normalmente utilizam-se de fotografias, desenhos e cartas como meio de comunicação e interpretação dessas realidades.

Geografia Ensino \& Pesquisa, v. 17, n.1 p. $71-80$, jan./abr. 2013

Ferreira, R. V. 
Tuan (1980) pontuou que, no espaço, os objetos percebidos pelo homem têm relação com as dimensões do corpo e do ambiente onde vivem. A mente humana não é capaz de abstrair distâncias da ordem de milhares de quilômetros, ou superfícies de milhões de quilômetros quadrados, pois são dimensões que ultrapassam 0 alcance da visão da paisagem. No entanto, as necessidades humanas de trânsito quase sempre se deram em distâncias que excederam 0 alcance da vista, ultrapassando assim o entorno imediato da aldeia e da comunidade. A ampliação do movimento pelo espaço organizou na mente humana um pensamento estratégico, que foi o de segmentar 0 espaço em parcelas conhecidas e referenciadas por marcos (montanhas, rios, floresta, pastagem, etc.). Quanto as direções, essas foram formatadas em 4 orientações que, na maioria das culturas, se resumem aos eixos cardinais. Um exemplo notável de como a habilidade espacial pode se desenvolver é citado pelo próprio Yi-fu Tuan (ibid. p.40), quando apresenta o caso do grupo esquimó Aivilik, habitante da llha de Southampton na Baía de Hudson (Canadá). Ao serem solicitados para desenhar a forma de sua ilha natal, os nativos produziram esboços que demonstraram notável semelhança com as formas em escala cartográfica. Os desenhos apresentaram maiores detalhes dos contornos, porém, muito exagero na escala na região que corresponde a península Bell, local da aldeia, e, simplificações das formas e menor precisão de contornos nas regiões mais distantes a essa península (figura 2). Esse exemplo reitera a ideia de que a inteligência espacial é uma faculdade humana que atende as necessidades básicas da vida e reflete como as diferentes sociedades se relacionam com o espaço conhecido. No caso dos Aivilik o local de habitação é, obviamente, o mais conhecido e, portanto, espacialmente mentalizado de uma forma mais detalhada, refletindo nos esboços desenhados. 0 mais surpreendente desta experiência é o fato de a referida ilha ter $41.214 \mathrm{~km}^{2}$, que corresponde, aproximadamente à área do Estado do Rio de Janeiro (43.696 km²).

Figura 2 - Ilha de Southampton, Baía de Hudson (Canadá). (A) e (B) esboços realizados pelos nativos Aivilik em 1929;

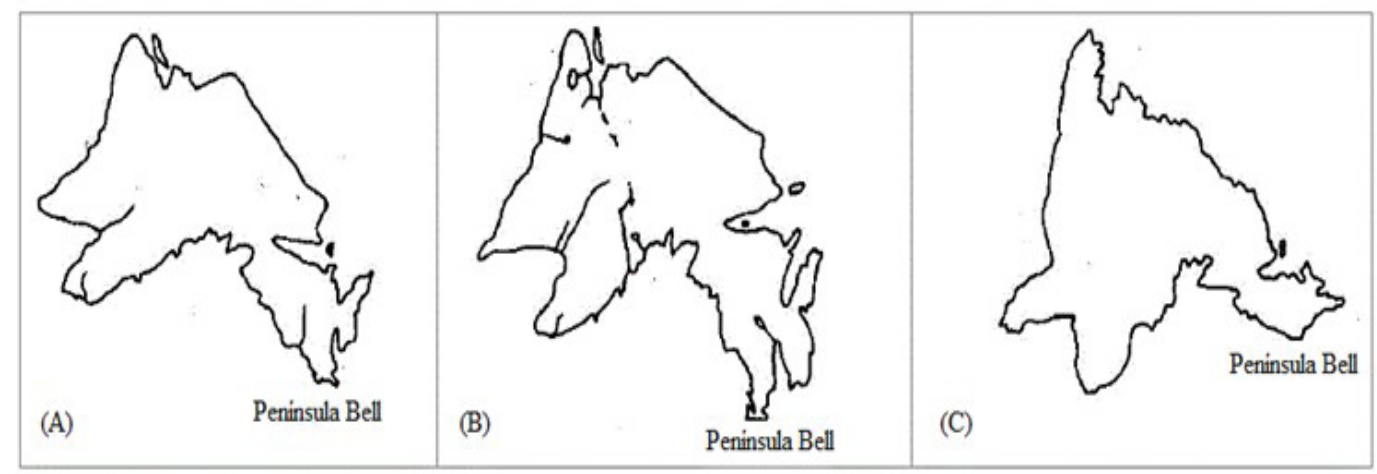

(C) Forma desenhada com base em fotografias aéreas. (modificado de Tuan, 1980)

O exemplo anterior mostra que a propensão humana para a construção de esquemas mentais, tem sido provavelmente, subestimada pelos programas que sistematizam conhecimentos cartográficos e os aplicam nas aulas de Geografia. Talvez esse seja um assunto que mereça maior aprofundamento.

Geografia Ensino \& Pesquisa, v. 17, n.1 p. $71-80$, jan./abr. 2013

A cartografia escolar $\mathrm{e}$ o desenvolvimento da habilidade espacial

\section{Desenvolvendo habilidades espaciais na escola}

Como fora visto, a visualização em cartografia implica na transposição mental do plano bidimensional para o tridimensional, e isso requer tanto do professor, quanto do aluno uma prática e aprendizado específicos. Tal aptidão não se constrói senão mediante a um programa de atividades caracterizado pela prática. Em um artigo publicado em língua portuguesa em 2008, Paul Vidal de La Blache pontua que algumas atividades que podem ser adotadas no cotidiano escolar servem para 0 
aprendizado das habilidades espaciais e devem ser realizadas de uma maneira prática, orientando os estudantes a reconhecer a toponímia dos lugares e relacionar com sua localização, direção e distância (LA BLACHE, 2008).

A asserção de La Blache chama atenção para propostas de um ensino de Geografia condizente com a realidade vivida pelos alunos. Nota-se, portanto, que esta não é uma proposição nova no ensino de Geografia, ou uma discussão que passou a ocupar a pauta de debates do aprendizado dessa disciplina somente a partir da década de 1970.

Originalmente escrito na década de 1950, a obra de Zoe Thralls (1965) traz importantes considerações sobre o ensino da Geografia e faz apontamentos sobre a necessidade de se tratar das habilidades espaciais pela leitura de mapas, estudos do meio e reconhecimento da paisagem.

Destaque-se aqui que a aquisição da habilidade espacial não se constrói em poucas aulas, e jamais se desenvolverá plenamente se os programas continuarem a relegar 0 aprendizado das visualizações espaciais e cartográficas a momentos isolados do currículo escolar. Geralmente, os programas destinam momentos para o estudo dos mapas e da cartografia, atendendo apenas aos conteúdos de um currículo e não propriamente uma instrumentalização para 0 aprendizado dos diversos conteúdos da Geografia com o apoio dos mapas e representações cartográficas. Dessa forma, os propósitos da cartografia são rapidamente esquecidos, a não ser por breves resgates onde os professores mostram mapas e figuras nas aulas de Geografia, não raro, descoladas de uma reflexão crítica e sem o devido aprofundamento da leitura e interpretação das representações. É necessário reiterar constantemente o lastro espacial dos temas que são tratados no ensino de Geografia, e esclarecer que as questões referidas a sociedade e natureza se dão de forma concreta no espaço: seja por fluxos, extensão e localização.

Como tratar destas questões com os alunos e ainda manter princípios educativos fundamentais da reflexão crítica sobre as relações espaciais dadas entre sociedade e natureza? Esta talvez seja uma pauta para futuros debates acerca de uma proposição mais ampla para o ensino de Geografia. Aqui não se apresenta uma nova proposta de ensino dos mapas e das representações do espaço, mas faz-se um convite a reflexão sobre como se tem conduzido a abordagem deste assunto em sala de aula e ao longo da vida escolar dos estudantes dos níveis seriais mais adiantados. Nesse sentido, uma pauta para debates pode ser um ponto inicial para a reflexão.

\section{Considerações finais}

Até aqui se procurou apresentar alguns argumentos que encaminham para uma reflexão sobre o ensino de Geografia apoiado pelo uso de representações cartográficas. No caso desta disciplina, os mapas, as maquetes e as representações da paisagem apresentadas por meio de fotos, figuras e diagramas têm sido os recursos utilizados pelos docentes em sala de aula para ilustrar o espaço, mas talvez não tenham sido usados de maneira plena, de modo a oferecer meios para se chegar a explicações mais aprofundadas sobre a espacialização dos fatos e fenômenos geográficos.

No presente texto procurou-se mostrar que a habilidade espacial advém de uma cognição que pode ser desenvolvida e que, se ampliada, é possível que o aprendizado de Geografia, em seus diversos temas, seja mais significativo. No que diz respeito à "leitura" do espaço feita por meio de mapas e representações, a experiência tem demonstrado que há uma necessidade de debates e reflexões mais aprofundadas, sobretudo, para os níveis seriais finais do ensino básico. No entanto, esta é uma hipótese aventada com base no acompanhamento de bibliografia sobre 0 assunto, na experiência de dez anos lecionando Geografia para o ensino básico e cinco anos ministrando cartografia para cursos de licenciatura em Geografia.

Como proposta inicial, indica-se como temas para debate e reflexão:

- Organizar o pensamento sobre o estado da arte no que refere à inteligência espacial e debatê-lo no contexto do ensino de Geografia.

Geografia Ensino \& Pesquisa, v. 17, n.1 p. $71-80$, jan./abr. 2013

Ferreira, R. V.

ISSN 2236-4994 
- Considerar a possibilidade do desenvolvimento de linhas de pesquisa que tratem das habilidades espaciais como qualidades importantes para o aprendizado da Geografia.

- Repensar os programas de ensino de cartografia e recursos didáticos orientados a representação do espaço para os cursos de Licenciatura em Geografia.

- Pensar metodologias de aprendizado da cartografia e uso de representações pela Geografia escolar voltada para o aluno do ensino médio e da EJA.

O uso dos mapas e recursos de representação do espaço certamente acompanhará o ensino de Geografia, isso é um fato. Há uma tendência em se traduzir para o plano digital os recursos que antes eram usados em meio analógicos. Aquele que pensa em educação pode se beneficiar das novas tecnologias da informação para sistematizar suas atividades e criar novas metodologias de aprendizado. No entanto, é fundamental refletir sobre como se dá o processo de formulação de conceitos pelos indivíduos. No caso do ensino de Geografia, é possível que a construção do pensamento e da reflexão sobre os diferentes temas a ela relacionados possam estar sendo prejudicados por um esvaziamento do discurso espacial, e aqui se refere ao espaço geométrico, aquele passível de ser mensurado e dimensionado, sobre o qual se desenvolve a vida e as sociedades de produzem e reproduzem. $O$ discurso da globalização parece ter encurtado demais as distâncias, mas, como disse Doreen Massey (2008, p. 138), o tempo não aniquilou o espaço, e sim multiplicou as possibilidades vivência e de reconhecimento dos variados ambientes. Talvez este seja um bom motivo para se pensar sobre o desenvolvimento das habilidades espaciais como recurso para melhor compreender os fatos e fenômenos geográficos e as dimensões dos espaços que são tangíveis aos alunos.

\section{Referências Bibliográficas}

ALMEIDA, Rosângela Doin. Do desenho ao mapa: Iniciação cartográfica na escola. São Paulo, 2001.

ALMEIDA, Rosângela Doin; PASSINI, Elza Yasuko. O espaço geográfico: ensino e representação" São Paulo: Contexto, 1988, 90p.

CARROLL, John B. Human cognitive abilities: a survey of factoranalytic studies. New York: Cambridge University Press, 1993, 819p.

GARDNER, Howard. Inteligências Múltiplas: a teoria na prática. Porto Alegre: Artmed, 1995.

La BLACHE, Paul Vidal. $O$ ensino de Geografia na escola: o que é, e o que deveria ser. In: RESENDE, E. C.M.; FERREIRA, R. V. A Geografia fora da sala de aula. São Paulo: Necrópolis, p. 12-22, 2008.

MASSEY, Doreen. Pelo Espaço. Rio de Janeiro: Bertrand Brasil, 2008

PARK, Gregory, LUBINSKI, David, BENBOW, Camila. Recognizing spatial intelligence. In: Scien-

Geografia Ensino \& Pesquisa, v. 17, n.1 p. $71-80$, jan./abr. 2013

A cartografia escolar e o desenvolvimento da habilidade espacial tific American, novembro, 2, 2010. Disponível em: < http://www.scientificamerican.com/article. cfm?id=recognizing-spatial-intel>. Acesso em 12 de fevereiro de 2011.

SANTOS, Clézio. Cartografia temática no ensino médio: do tema à representação gráfica. Boletim de Geografia, v. 19, n. 2, p. 19-28, 2001.

SIMIELLI, M. E. R. Cartografia no ensino fundamental e médio". In: CARLOS, A. F. A. (Org). A Geografia em sala de aula. São Paulo: Contexto, 1999. 
SOUZA, Jose Gilberto de; KATUTA, Ângela Massumi. Geografia e conhecimentos cartográficos. São Paulo: Ed. Unesp 2001. 162 p.

THRALLS, Zoe. O ensino da Geografia. Porto Alegre: Globo, 1965.

TUAN, Yi-Fu. Topofilia: um estudo da percepção, atitudes e valores do meio ambiente. São Paulo: Difel, 1980.

\section{Correspondência:}

Ricardo Vicente Ferreira- Departamento de Geografia, Centro Educacional - Sala 327. Av. Getúlio Guaritá, nº 159 - Bairro Abadia, CEP: 38025-440, Uberaba-MG

E-mail: rvicenteferreira@yahoo.com.br

Recebido em 20 de junho de 2012.

Revisado pelo autor em 14 de novembro de 2012.

Aceito para publicação em 15 de janeiro de 2013. 